\begin{tabular}{|c|c|c|}
\hline $\begin{array}{l}\text { PKS } \\
\text { PUBLIC } \\
\text { KNDOLEDGE } \\
\text { PROJECT }\end{array}$ & $\begin{array}{l}\text { Revista de GEOGRAFIA } \\
\text { (RECIFE) } \\
\text { http://www.revista.ufpe.br/revistageografia }\end{array}$ & $\begin{array}{l}\text { OJS } \\
\text { OPEN } \\
\text { JORNAL } \\
\text { SYSTEMS }\end{array}$ \\
\hline
\end{tabular}

\title{
GEOMORFOLOGIA ESTRUTURAL, NEOTECTÔNICA E CARSTE: EXEMPLOS NO NORDESTE BRASILEIRO
}

\author{
Rubson Pinheiro Maia \\ Universidade Federal do Ceará. Email:rubsonpinheiro@yahoo.com.br
}

Artigo recebido em 10/07/2018 e aceito em 11/08/2018

\begin{abstract}
RESUMO
O controle estrutural sobre o relevo pode ser compreendico como qualquer carcterisitca intrisseca da rocha que tenha repercussão na morfologia. Estruturas associadas a tectônica também podem ter significado geomorfológico, sobretudo em margens ativas ou em zonas de deformação. No nordeste setentrional brasileiro, estruturas deformacionais relacionadas à orogenia brasiliana, ao rifteamento da margem no Jurássico-Cretáceo, e a reativação cretácea e cenozoica controlam diversas feições da morfologia. Essas feições incluem alinhamento de cristas residuais, vales estruturais, escarpas de falha e são associadas às faixas móveis pré-cambrianas e seus trends estruturais reativados no Cretáceo e no Cenozoico com repercussão direta no ambiente carstico. O presente texto, discorrerá acerca do condicionamento morfoestrutural do relevo com ênfase no papel exercido pelas estruturas de deformação rúpteis e dúcteis do embasamento cristalino pré-cambriano. A exumação em zonas de deformação de direção NE-SW e E-W origina trends de lineamentos que confinam os canais de drenagem orientando a dissecação e por vezes a agradação fluvial. Isso resulta em sequencias de cristas e vales que confinam os canais de escoamento, passando esses a serem indicadores dos planos de deformação. Esse contexto estende-se para os ambientes sedimentares na forma de controle sobre a dissecação que passa a ocorrer orientada segundo os planos de falhas, formando vales encaixados que constituem a expressão geomorfológica da reativação frágil de zonas de cisalhamento transcorrentes nas unidades sedimentares.
\end{abstract}

Palavras-chave: Geomorfologia, Nordeste, Tectônica.

\section{STRUCTURAL GEOMORPHOLOGY, NEOTECTONIC AND KARST: EXAMPLES IN THE NORTHEAST OF BRAZIL}

\begin{abstract}
The structural control over the relief can be understood as any intrinsic rock character that has repercussion in the morphology. Structures associated with tectonics may also have geomorphological significance, especially in active margins or deformation zones. In northern Brazil, deformational structures control various features of the morphology. These structures are ductile shear zones and regional foliations formed during the brasiliano orogeny in the late proterozoic, and faults formed during the rifting of the margin in the Jurassic - cretaceous and in the late cretaceous and Cenozoic. The morphology features related to these structures include mainly residual alignment of ridges, fault-controlled valleys, and structural fault scarps. In this perspective, this paper presents a review about the morphostrutural control played by brittle and ductile basement structures on the relief in northeastern brazil. Our study indicates that continental denudation have been controled by both differential erosion and tectonics. In this aspect, the exhumation along NE-SW and E-W striking shear zones originates lineaments, which confine the drainage channels and guide the dissection and sometimes fluvial aggradation. This process results in ridges and valleys that control the flow channels, which become indicators of shear zones and faults. This process is also observed in sedimentary basins, where dissection along fault zones form tectonic valleys that constitute the geomorphic expression of the fault reactivation.
\end{abstract}

Keywords: Geomorphology, Northeastertn Brazil, Morphotectonics. 


\section{INTRODUÇÃO}

Vários condicionantes litológicos e estruturais influenciam os processos de erosão diferencial do embasamento. No Nordeste Brasileiro é possível identificar muitos exemplos onde a erosão têm distinguido formas de relevo segundo seus controles lito-estruturais. Esses controles são representados principalmente pelo grau de faturamento, pela litologia/faciologia e pelos planos de foliação ígnea, metamórfica e de acamamento, nos terrenos sedimentares. $\mathrm{O}$ presente artigo fará uma análise de diferentes padrões de relevo que se desenvolvem em tipos litológicos distintos ou em uma mesma unidade litológica a partir da correlação de fácies. Nesse sentido, a manutenção de topografias elevadas no embasamento resulta da menor erosão em núcleos de resistência mecânica aos processos denudacionais. Essa resistência se deve sobretudo as características litológicas, faciológicas, petrográficas e estruturais que se somam para aumentar ou diminuir a coesão físico-química da rocha frente à meteorização.

Dois aspectos são importantes para este controle. O primeiro controle é exercido pela erosão diferencial. Nesse aspecto as Zonas de cisalhamento são geralmente marcadas por corpos graníticos, que são mais resistentes à erosão originando dessa forma sobressaltos topográficos. O segundo controle é aquele dado pela reativação frágil das zonas de cisalhamento. Este por sua vez têm gerado abatimentos e soerguimentos segundo os planos de deformação brasiliana originando dessa forma um relevo notoriamente marcado por trends de lineamentos estruturais.

Em termos geomorfológicos, lineamentos representam comumente variações na elevação dos terrenos, alinhamento de cristas, segmentos de escarpas, trechos de drenagem e vales que por refletirem as principais linhas de fraqueza regionais podem indicar locais de ocorrência de estruturas geológicas importantes para comprovar a influência estrutural e/ou tectônica na evolução do relevo. Desse modo, a análise de domínios de lineamentos em escala regional, tem sido mostrada como uma ferramenta útil para investigar a relação entre a Geomorfologia e a Tectônica.

O texto ora apresentado, apresentado originalmente no XII Simpósio Nacional de Geomorfologia, ocorrido em 2018, proporá uma análise acerca do condicionamento litoestrutural sobre os processos erosivos e denudacionais no Nordeste Brasileiro. Tal análise basear-se-á na configuração do modelado em escala regional e local, enfatizando a relação entre forma, estrutura e litologia. 


\section{OS CONTROLES LITOESTRUTURAIS}

Em termos evolutivos, os principais eventos de evolução tectônica da Província Borborema podem ser distinguidos da seguinte forma: 1 - Orogênese Brasiliana, derivada da colagem tectônica brasiliana/panafricana de 600 Ma (Brito Neves et al., 2000), a qual foi acompanhada de um importante plutonismo granítico (Angelim, et al., 2006). 2 Fragmentação do Megacontinente Gondwana resultando na separação Brasil - África (Matos, 2000) e 3 - Reativações tectônicas cenozoicas (Bezerra e Vita Finzi, 2000) condicionam a evolução geomorfológica através das alterações dos níveis de base induzindo a dissecação e agradação (Maia et al., 2010).

Essa sequência de eventos tectônicos é a principal responsável pelas linhas mestras do relevo que condicionam a evolução geomorfológica atual, que é marcada pelo controle exercido sobre os processos denudacionais cenozoicos. Tal controle resulta do condicionamento estrutural da evolução geomorfológica, sobretudo nas áreas de deformações tectônicas como nas zonas de cisalhamento. Segundo Trindade et al., (2008) as zonas de cisalhamento são condutos por onde pode circular um grande volume de fluidos, constituindo assim áreas que foram afetadas por deformação dúctil (Passchier et al., 1993). Nessas zonas a configuração litológica heterogênea disposta em faixas paralelas direcionadas segundo os planos de deformação e os sistemas de falhas e fraturas condicionam os processos erosivos que passam a expressar no relevo as direções da foliação metamórfica e dos trends estruturais. Isso acontece por que nas zonas de cisalhamento pode ocorrer a ascensão de magma granítico e seu posterior deslocamento horizontal originando intrusões lineares. Esse deslocamento foi comprovado a partir do paralelismo existente entre foliação magmática e milonítica (Neves, 1991). Dessa forma as zonas de deformação tectônica criam tanto lineamentos de rochas miloniticas quanto graníticas.

As zonas de cisalhamento se formaram em nível crustal profundo. Entretanto foram reativadas em vários níveis crustais. Estas reativações produziram deformações no campo dúctil-rúptil e rúptil. Ambos esses processos são potenciais geradores de trends de lineamentos que para a geomorfologia, são considerados importantes feições relacionadas a deformação tectônica. Tais deformações são associadas a estruturas de subsuperfície, sendo passíveis de serem identificáveis no terreno e em imagens de sensores remotos.

Assim é importante destacar a natureza estrutural do relevo seja através do controle exercido na erosão diferencial em virtude da heterogeneidade litológica associada a zonas de deformação dúctil e aos planos de foliação, seja através dos efeitos das reativações tectônicas. 
No Nordeste Brasileiro as reativações tectônicas cenozoicas são responsáveis pelo rejuvenescimento de maciços cristalinos através de seu soerguimento ou pelo abatimento de blocos por subsidência que resulta na formação de pequenas bacias interiores.

Os efeitos das reativações tectônicas na morfologia, na drenagem e nos ambientes de sedimentação de diversas bacias no nordeste setentrional brasileiro foram analisados por Bezerra e Vita-Finzi (2000); Bezerra et al. (2001, 2008); Furrier et al., (2006) Nogueira et al., (2010), Moura Lima et al. (2010), Lima, (2010) Rossetti et al. (2011) e Maia e Bezerra, (2012) demonstraram que a relação entre a tectônica cenozoica e os depósitos neogênicos (Formação Barreiras) e quaternários, é responsável pelas conformidades entre a disposição dos vales, falésias e as falhas neotectônicas. Conforme esses trabalhos, essa conformação indica a relação genética existente entre alinhamentos mais antigos e a morfologia atual dos vales e das escarpas litorâneas. Vários alinhamentos de vales e áreas deprimidas direcionamse segundo as orientações de falhas do embasamento pré-cambriano e cretáceo o que pode representar uma reativação recente dessas linhas de fraqueza (Moura Lima, et al., 2010).

Os lineamentos de direção NE-SW e E-W em muitos casos representam a expressão em superfície, da deformação brasiliana de caráter dúctil/rúptil reativadas no cretáceo e no cenozoico. Esses lineamentos compreendem trends de falhas que exercem uma importante influencia no controle estrutural de drenagem, na dissecação e na deposição quaternária. Exemplos dessa disposição morfoestrutural são comumente encontrados nas áreas erosionais representadas pelas depressões sertanejas e os maciços cristalinos.

Na Província Borborema, extensas zonas de cisalhamento transcorrentes brasilianas a seccionam nas direções E-W e NE, zonas estas que, em geral controlam o alojamento de diversos corpos granitoides (Nascimento, 1998). Disso decorre o caráter do relevo ser comumente disposto em sequencias de cristas e vales orientados segundos os trends de lineamentos. Esses trends são representados por planos de foliação, por cristas quartizíticas ou de micaxistos, por intrusões graníticas e por planos de milonitização. Assim originam-se lineamentos paralelos, de resistência diferenciada a denudação geoquímica ou física favorecendo através da erosão diferencial o desgaste das faixas menos tenras segundo os planos de deformação e a manutenção dos corpos intrusivos, que passam a ser expressos no relevo como cristas residuais de origem estrutural.

O resultado final da atuação da erosão é o desaparecimento do relevo e o retorno da crosta a sua espessura inicial, anterior ao evento deformacional. Isso implica entre outras coisas, em que o substrato de subsuperfície, aparecerá em superfície (Arthaud, 2007). Dessa 
forma a erosão de zonas de cisalhamento dúcteis pré-cambrianas conduz a progressiva exumação de maciços cristalinos, descritos tradicionalmente como residuais. Essa exumação possibilitou através da erosão diferencial a formação de trens de lineamentos geomorfológicos dispostos em formas lineares positivas e negativas associadas aos planos de deformação brasiliana.

Dessa forma, os planos de deformação brasiliana condicionam em escala regional diversas morfologias, principalmente aquelas associadas as zonas de cisalhamento dúcteis onde o relevo é caracterizado por cristas simétricas com vertentes de declividade acentuadas dispostas de forma contínua.

Os ambientes sedimentares também têm revelado importantes indicadores de como os processos de reativação cenozoica tem condicionado a evolução de relevo. Nesses ambientes a repercussão dessas reativações pode ser constatada a partir da orientação da dissecação e da consequente deposição quaternária. Dessa forma, a geomorfologia do Nordeste setentrional, tanto no embasamento pré-cambriano quanto nos ambientes sedimentares (Bacias Paleomesozóicas e depósitos cenozoicos) é notoriamente condicionada pela disposição morfoestrutural. Nesse aspecto, as maiores bacias hidrográficas do Nordeste setentrional estão diretamente condicionadas por falhamentos e por zonas de cisalhamento dúcteis. São exemplos dessas drenagens o Rio Acaraú, na porção norte da área de estudo, que possui seu vale encaixado sobre o lineamento transbrasiliano. O Rio Jaguaribe que desenvolve seu baixo e médio curso sobre a falha de denominação homônima, em uma depressão entre as zonas de cisalhamento Senador Pompeu e Portalegre. Os vales dos Rios Apodi-Mossoró e PiranhasAçu, ambos encaixados no sistema de falhas não aflorantes da fase rifte na Bacia Potiguar. Neste caso, a reativação de falhas da fase rifte é responsável por formação de altos e baixos topográficos da Bacia Potiguar, influenciando assim na configuração da drenagem.

Com exceção da Planície costeira, as demais unidades apresentam padrões de orientação de dissecação variando de N-S, NE-SW e E-W conforme a direção das zonas de cisalhamento dúcteis pré-cambrianas. Nas áreas dos Maciços e Depressões, a exumação das zonas de cisalhamento controlam feições da morfologia, formando vales e cristas de mesma direção. Esses cinturões de deformação individualizam setores mais dissecados onde o controle estrutural é menos evidenciado. Trata-se das depressões sertanejas que se distribuem nas áreas interioranas na forma de extensas superfícies aplainadas interrompidas por relevos isolados, compostos por maciços graníticos que constituem rochas mais resistentes que as do 
entorno rebaixado. Nessa unidade do relevo predominam os processos de dissecação sobre os de agradação gerando a exposição contínua do embasamento.

A topografia na depressão sertaneja varia de plana a suavemente ondulada compondo superfícies situadas entre 50 e 300 metros de altitude, que partem da borda dos planaltos residuais na forma de depressões periféricas. A complexidade litológica associada às depressões sertanejas dificulta sua caracterização geológica. Contudo, é possível destacar a predominância de um substrato metamórfico variado onde a mineralogia das rochas, resultantes do metamorfismo que ocorreu no Pré-cambriano, controla a erosão diferencial que ocorreu no Cenozoico.

Outras formas de relevo associadas aos vales e aos ambientes de deposição quaternários podem apresentar os efeitos do tectonismo cenozoico em escala local, como níveis de terraços escalonados, anomalias de drenagem, falésias e domos estruturais.

Nas áreas dos depósitos cenozoicos os efeitos do condicionamento neotectônico pode ser manifestar sobre os processos erosivos ou agradacionais. Tal condicionamento é representado pelos níveis de terraços escalonados como nos vales do Rio Jaguaribe PiranhasAçu e pelo controle estrutural de falésias nos casos em que estas se situam em zonas de falhas ativas, como as falésias do litoral da Bacia Potiguar. Na unidade dos planaltos desenvolvidos nas bacias paleo-mesozoicas, as unidades ocorrem a melhor representatividade dos eventos deformacionais pós-rifte. Tais eventos ocorrem sobre controle estrutural que condiciona a circudenudação dessas bacias. São exemplos desses processos o setor norte do Platô da Ibiapaba, o planalto formado na Bacia do Araripe, a cuesta da Bacia Potiguar e seu reverso repleto de lajedos carsticos intensamente falhados. Nas unidades dos maciços, em geral o relevo representa a disposição morfoestrutural através das escarpas, linhas de cristas e vales orientados segundo os planos de deformação tectônica. Nas demais unidades não há evidencias de controle estrutural do relevo em termos morfogenéticos e morfoevolutivos.

\section{CONSIDERAÇÕES FINAIS}

A principal contribuição deste trabalho é a incorporação de processos de deformação de superfície e subsuperfície no condicionamento do relevo setentrional da região Nordeste do Brasil. Neste aspecto o relevo é influenciado por estruturas de deformação tectônica de idade pré-cambriana reativadas no cretáceo e no cenozoico. Essas deformações incluem alinhamentos de cristas residuais que confinam canais de drenagem e constituem a expressão geomorfológica das intrusões graníticas nas zonas de cisalhamento transcorrentes de direção 
NE-SW e E-W. Por sua vez essas zonas de cisalhamento podem ser consideradas em termos geomorfológicos as equivalentes profundas, dissecadas, das grandes falhas de rejeito direcional observadas em níveis crustais mais rasos.

Em termos gerais, o controle estrutural do relevo é evidenciado a partir da dissecação sobre estruturas tectônicas dúcteis e rúpteis. No primeiro caso ocorrem principalmente os alinhamentos de cristas e os vales orientados originando trends de lineamentos (NE-SW e EW) positivos e negativos que passam a evidenciar em suas formas a trama estrutural vigente. Já o segundo caso, as deformações de caráter rúptil condicionam a dissecação e a deposição quaternária. Isso ocorre através do controle estrutural de drenagem que os rios apresentam ao atravessarem zonas de falhas ativas. Os trends de fraturas, os planos de foliação aumentam a susceptibilidade da rocha ao fraturamento termoclástico acelerando a saprolitização. Essa distribuição diferencial dos trends de lineamentos associados ao quadro de variabilidade climática imprimiu fases pedogênicas acompanhadas de fases erosivas. Essa variabilidade possibilitou a progressiva exumação dos núcleos granitoides menos fraturados originando assim muitos dos maciços do Nordeste semiárido brasileiro. As feições erosionais que os modelam podem ter sua gênese associadas à variabilidade faciológica e textural das unidades litológicas em que ocorrem.

\section{REFERENCIAS:}

AB SÁBER, A.N; BIGARELLA, J.J. Considerações sobre a geomorfogênense da Serra do Mar. Boletim Paranaense de Geografia n.4/5 p94-110, 1961.

AB SÁBER, A. N. (1969). Participação das superfícies aplainadas nas paisagens do Nordeste Brasileiro. Bol. Geomorfologia, IGEOG-USP, SP, n 19, 38p. 1969.

ALMEIDA, F. F. M.; BRITO NEVES, B.B.; CARNEIRO, C.D.R. The origin and evolution of the South American Platform. Earth Science Reviews, 50: 77-111, 2000.

ALMEIDA, F. F. M., HASUI, Y., NEVES, B. B. B., FUCK, R. A. Províncias Estruturais Brasileiras - Atas VIII Simp. Geol. Nordeste, Anais. Campina Grande, 363-391, 1977.

ALMEIDA, F. F. M., HASUI, Y., NEVES, B. B. B., FUCK, R. A. Brazilian structural provinces: an introduction. Earth Sciences Reviews, 17: 1-29, 1981.

ALMEIDA, F. F. M; BRITO NEVES, B.B; CARNEIRO, C.D.R. The origin and evolution of the South American Platform. Earth Science Reviews, 50: 77-111. 2000.

ANDRADE G.O; LINS R. Introdução à morfoclimatologia do Nordeste do Brasil Arquivos do Instituto de Ciências da Terra, Recife (3-4): 11-28, 1965.

ANGELIM, L.A.A., MEDEIROS, V.C., NESI, J.R. 2006. Programa Geologia do Brasil PGB. Projeto Mapa Geológico e de Recursos Minerais do Estado do Rio Grande do 
Norte. Mapa Geológico do Estado do Rio Grande do Norte. Escala 1:500.000. Recife: CPRM/FAPERN, 2006.

ARTHAUD, M. H. Evolução neoproterozóica do grupo Ceará (domínio Ceará central, NE Brasil): da sedimentação à colisão continental brasiliana. $170 \mathrm{f}$. Tese (Doutorado em Geociências)-Universidade de Brasília, Brasília, 2007.

ARARIPE, P.T.; FEIJÓ, F.J. Bacia Potiguar. Boletim de Geociências, RJ, v.8, nº.1, 1994.

BEZERRA, F. H. R.; VITA-FINZI, C. How active is a passive margin? Paleoseismicity in Northeastern Brazil. Geology. v. 28: 591-594, 2000.

BEZERRA, F. H. R.; AMARO, V. E.; VITAFINZI, C.; SAADI, A. Pliocene-Quaternary fault control of sedimentation and coastal plain morphology in NE Brazil.Journal of South American Earth Sciences. v14: 61-75, 2001.

BEZERRA, F. H. R.; NEVES, B. B. B.; CORREA, A. C. B.; BARRETO, A. M. F.; SUGUIO, K. Late Pleistocene tectonic-geomorphological development within a passive margin - the Cariatá trough, northeastern Brazil. Geomorphology. 01: 555-582, 2008.

BIGARELlA, J. J. Estrutura e Origem das Paisagens Tropicais. Vol.1. Florianópolis: Ed. UFSC. 1994.

BIGARELlA, J. J. Estrutura e Origem das Paisagens Tropicais. Vol.3. Florianópolis: Ed. UFSC. 2003.

BIZZI, L. A., SCHOBbEnHAUS, C., VIDOTTI, R. M., GONÇALVES, J.H. (Org.). Geologia, Tectônica e Recursos Minerais do Brasil - Texto, Mapas e SIG. 2003.

BRITO NEVES, B.B. América do Sul: quatro fusões, quatro fissões e o processo acrecionário andino. Bahia. VII Simpósio Nacional de Estudos Tectônicos, Anais SBG. 11-13. 1999.

BRITO NEVES, B.B., SANTOS, E. J., VAN SCHMUS, W. R. Tectonic history of the Borborema Province, northeastern Brazil. In Cordani, U.G., Milani, E.J., Thomaz Filho, A., Campos, D.A. (Eds.) Tectonic Evolution of South America. Rio de Janeiro, 31 International Geological Congress, p.151-182, 2000.

CASTRO ET AL 2008, 2012

CORREA, A.C.B; TAVRES, B.A.C; MONTEIRO, K.A; CAVALCANTI, L.C.S; LIRA, D.R. Megageomorfologia e Morfoestrutura do Planalto da Borborema. Revista do Instituto Geológico, São Paulo, 2010.

CORSINI, M., LAMBERT DE FIGUEIREDO, L., CABY, R., FÉRAUD, G., RUFFET, G., VAUCHES, A., Thermal history of the Pan/African - Brasiliano Borborema province of the northeast Brazil, deduced from ${ }^{40} \mathrm{AR} /{ }^{39 \mathrm{AR}}$ analysis. Tectonophysics, 285. 1998.

FURRIER, M.; ARAÚJO, M. E.; MENESES, L. F. Geormorfologia e Tectônica da Formação Barreiras no Estado da Paraíba. Geologia USP, Sér. Cient., São Paulo, v.6, n.2, p. 61-70, 2006.

GURGEL, S. P. P. ; BEZERRA, F. H. R. ; CORRÊA, A. C.B. ; MARQUES, F O. ; MAIA, R. P. . Cenozoic uplift and erosion of structural landforms in NE Brazil. Geomorphology (Amsterdam), v. 186, p. 68, 2013.

KING, L. C. A geomorfologia do Brasil Oriental. Revista Brasileira de Geografia. 18:2, 147-265, 1956. 
JORDAN, G.; SCHOTT, B. Application of wavelet analysis to the study of spatial pattern of morphotectonic lineaments in digital terrain models. A case of study. Remote Sensing of Environment, 94. p. 31-38. 2005.

LIMA, C. C. U. Evidências da Ação Tectônica nos Sedimentos da Formação Barreiras Presentes do Litoral de Sergipe ao Norte da Bahia. Revista de Geografia (Recife), v. Esp.01, p. 148-160, 2010.

MABESSONE, J. M; CASTRO, C; Desenvolvimento Geomorfológico do Nordeste Brasileiro, Boletim do núcleo Nordeste da Sociedade Brasileira de Geologia. 3, 1975.

MABESSONE, M. J.; História Geológica da Provincia Borborema (NE do Brasil) Revista de Geologia UFPE, 15, 2002.

MAIA, R. P.; BEZERRA, F. H. ; SALES, V. C. Geomorfologia do Nordeste: Concepções clássicas e atuais acerca das superfícies de aplainamento. Revista de Geografia (Recife), v. 27, p. -6--19. 2010.

MAIA, R. P. ; Bezerra, F. H. R . Geomorfologia e Neotectônica da Bacia Hidrográfica do Rio Apodi-Mossoró NE/Brasil. Mercator (Fortaleza. Online), v. 11, p. 209-228, 2012.

MATOS, R. D. M. Tectonic evolution of the equatorial south atlantic, in: Atlantic Rift in Continental Margins. American Geophysical Union. p.331-351, 2000.

MONIÉ, P., CABY, R., ARTHAUD, M., The neoproterozoic orogeny in northeast Brazil: 40Ar/39Ar ages and petrostructural data from Ceará. Precambrian Research, 81, 1997.

MOURA-LIMA, E. N.; SOUSA, M. O. L.; BEZERRA, F. H. R.; AQUINO, M. R.; VIEIRA, M. M.; LIMA-FILHO, F. P.; FONSECA, V. P.; AMARAL, R. F. Sedimentação e deformação Tectônica cenozóicas na porção central da Bacia Potiguar. Geologia USP. Série Científica, v. 10, 2010.

MATOS, R. M. D. The Northeast Brazilian Rift System. Tectonics. 11 (4): 766-791, 1992.

MATOS, R. D. M, Tectonic evolution of the equatorial south atlantic, in: Atlantic Rift in Continental Margins. American Geophysical Union, p331-351. 2000.

NASCIMENTO, R.S.C; Petrologia dos Granitóides Brasilianos associados a zonas de cisalhamento Remígio-Pocinhos (PB). Dissertação de Mestrado, Programa de Pósgraduação em Geodinâmica e Geofísica. PPGG-UFRN, Natal, RN, 1998.

NEVES, S.P. A zona de cisalhamento tauá, ceará: sentido e estimativa do deslocamento, evolução estrutural e granitogênese associada. Revista Brasil.eira de Geociências. 21 Vol. 2, 1991.

NOGUEIRA, F. C.; BEZERRA, F. H. R.; FUCK, R. A. Quaternary fault kinematics and chronology in intraplate northeastern Brazil. Journal of Geodynamics, v. 49, p. 79-91, 2010.

NOGUEIRA, F.C.C; BEZERRA, F.H.R; CASTRO, D.L. de. 2006. Deformação Rúptil em Depósitos da Formação Barreiras na Porção Leste da Bacia Potiguar. Revista do Instituto de Geociências-USP. Geol. USP Ser. Cient., São Paulo, v.6, n. 2, p. 51-61.

O'LEARY, D.W., FRIEDMAN, J.D., POHN, H.A. Lineament, linear, lineation: some proposed new standards for old terms. Geological Society of America Bull., 87:1463-1469. 1976. 
OLIVEIRA, R. G. MEDEIROS, W.E. Evidences of buried loads in the base of the crust of Borborema Plateau (NE Brazil) from Bouguer admittance estimates. Journal of South American Earth Scienses. V37, 2012.

PASSCHIER, C.W; SIMPSON, C. Porphyroclast systems ans kinematic indicators. Journal Estructural Geology, 1993.

PEULVAST, J. P.; CLAUDINO SALES, V. Stepped surfaces and Paleolandforms in the Northern Brasilian <Nordeste>: Constraints on models of morfotectonic evolution. Geomorphology, v. 3: 89-122, 2003.

ROSSETTI, D. F.; BEZERRA, F. H.; GÓES, A. M.; Brito-Neves, B.B. Sediment deformation in Miocene and post-Miocene strata, Northeastern Brazil: evidence for paleoseismicity in a passive margin. Sedimentary Geology, v. 235, p. 172-187. 2011.

SAADI, A. \& TORQUATO, J.R. Contribuição à neotectônica do Estado do Ceará. Revista de Geologia, Fortaleza-CE. 5: 5-38, 1994.

SABINS, Jr., F.F. Remote sensing: principles and interpretations. Freeman and Company, 494p. 1996.

TRINDADE, I. V; MARTINS SÁ, J; MACEDO' M.HF; Comportamento de elementos químicos em rochas mineralizadas em ouro na Faixa Seridó, Província Borborema. Revista Brasileira de Geociências, V38, n2, SP, 2008.

VAUCHES, A., NEVES, S., CABY, R., CORSINI, M., EGYDIO-SILVA, M., ARTHAUD, M., AMARO, V., The Borborema shear zone system, NE Brazil. Journal of South American Earth Sciences, 8, 1995. 